\title{
Genes de la obesidad monogénica
}

\section{Monogenic obesity genes}

\section{P. Miguel-Soca ${ }^{1}$, L. Cruz-Lage ${ }^{2}$, I. Edwards-Scringer ${ }^{3}$}

\section{Sr. Director:}

Hemos leído la interesante revisión de González Jiménez y col $^{1}$ sobre la obesidad monogénica y el papel del sistema leptinamelanocortina en la ingestión de alimentos y el control del peso corporal. Los autores citados $^{1}$ describen correctamente el papel de los principales genes y los mecanismos básicos de control de la ingesta de alimentos.

La obesidad por su carga económica y morbilidad constituye un importante problema de salud pública internacional. Aunque los factores ambientales como la escasa actividad física y la sobrealimentación contribuyen al incremento de personas obesas y con sobrepeso, se estima que los factores genéticos representan del 40$90 \%$ de la variación poblacional del índice de masa corporal (IMC) ${ }^{2}$. La identificación de los genes que participan en la susceptibilidad genética a la obesidad incrementa nuestro conocimiento de la biología del balance energético y la identificación de dianas moleculares para la intervención terapéutica futura.
La obesidad según su etiología genética se clasifica en monogénica, sindrómica y poligénica. González Jiménez y col ${ }^{1}$ se centran en la obesidad monogénica no sindrómica; en esta carta nos referiremos a otros genes de la obesidad no desarrollados por estos autores y a algunas formas sindrómicas de obesidad que, a nuestro juicio, complementaría la excelente revisión analizada.

Múltiples variantes genéticas se asocian con la obesidad en adultos y en algunos casos de obesidad mórbida en niños, aunque se han logrado menos progresos para establecer las influencias genéticas en las formas comunes de obesidad de inicio precoz. Un reciente meta-análisis encontró los locus asociados al incremento IMC: FTO, TMEM18, POMC, MC4R, FAIM2, TNNI3K y SEC16B ${ }^{3}$.

En estudios recientes, el gen asociado a la obesidad y la masa grasa (FTO), localizado en el cromosoma 16q12.2, se relaciona con un mayor IMC y obesidad en estudios transversales. También se ha sugerido que los alelos de riesgo de adiposidad de este gen predisponen a la diabe-
1. Universidad de Ciencias Médicas, Holguín, Cuba.

2. Facultad de Estomatología, Holguín, Cuba.

3. Universidad de Ciencias Médicas, Holguín, Cuba.

Recepción: 8 de enero de 2013

Aceptación definitiva: 15 de enero de 2013

\section{Correspondencia:}

Pedro Enrique Miguel Soca Universidad de Ciencias Médicas.

Avda. Lenin, 4 Esquina Aguilera.

Holguín 80100 CUBA

E-mail: soca@ucm.hlg.sld.cu 
tes mellitus, la hipertensión arterial y los eventos cardiovasculares en poblaciones de alto riesgo ${ }^{4}$.

El gen FTO se identificó primero en el cromosoma 8 en ratones, cuya delección era responsable del fenotipo de dedos fusionados. Los ratones homocigóticos para la delección murieron en la gestación con severas malformaciones, defectos del desarrollo, polidactilia y retraso del crecimiento $^{2}$. El producto del gen FTO parece una 2-oxoglutarato oxigenasa, una enzima implicada en la reparación del ADN, el metabolismo de los ácidos grasos y en modificaciones postraduccionales de las proteínas $^{5}$.

Otros genes implicados en la obesidad codifican a las proteínas desacopladoras mitocondriales: UCP1, UCP2, UCP3, UCPAOR, UCP4 y UCP5. El gen de UCP1 de la más conocida proteína desacopladora mitocondrial se localiza en el cromosoma 4q28-q31, se extiende por $13 \mathrm{~Kb}$ y contiene una región transcripta que cubre $9 \mathrm{~Kb}$ con 6 exones.

La UCP1 es una proteína desacopladora del tejido adiposo pardo, exclusiva de los mamíferos, que interviene en la termogénesis al desacoplar el transporte de electrones de la fosforilación oxidativa, lo que favorece la liberación de la energía en forma de calor ${ }^{6}$. El sistema nervioso simpático controla la expresión y activación de las proteínas desacopladoras como parte de la respuesta adaptativa a las bajas temperaturas y del control del balance energético ${ }^{7}$. Los ratones deficientes en UCP1 son sensibles al frío y más susceptibles a la obesidad inducida por la dieta ${ }^{6}$.

La obesidad monogénica no sindrómica se produce por alteraciones únicas de genes, pero a diferencia de la sindrómica no produce fenotipos característicos. Múltiples síndromes genéticos se manifiestan con obesidad como parte del cuadro clínico; aunque se presentan en un pequeño porcentaje de los niños obesos se acompañan de retraso mental, dismorfias y otras características.

El más frecuente de estos síndromes (1 en 10,000-25,000 nacimientos) es el síndrome de Prader-Willi, un trastorno auto- nómico dominante, que se caracteriza por obesidad, hiperfagia, hipotonía muscular, retraso mental, baja estatura e hipogonadismo, que se desarrolla entre los 12 y 18 meses de edad ${ }^{8}$. Habitualmente, este síndrome se produce por una delección de herencia paterna en la región cromosómica 15q11.2-q13 y menos frecuentemente por disomía uniparental materna; en raras ocasiones por otros defectos ${ }^{9}$.

Otro tipo de obesidad sindrómica se presenta en el síndrome de Cohen, una rara condición genética recesiva asociada con dismorfismo facial, retraso del desarrollo, hipotonía y anomalías oftalmológicas, debidas a mutaciones del gen $\mathrm{COH} 1$, que se localiza en el brazo largo del cromosoma 8, específicamente en $8 q 22.2^{10}$. El homólogo de $\mathrm{COH} 1$ en ratones se expresa en neuronas del cerebro postnatal y del adulto, lo que sugiere un papel en la diferenciación neuronal.

En resumen, el tema tratado por González Jiménez y col ${ }^{1}$ es complejo, muy amplio, con aspectos controversiales y no bien esclarecidos, además de su probable aplicación en la terapéutica de la obesidad, lo que justifica la intensa investigación a que está sometido en la actualidad.

\section{BIBLIOGRAFÍA}

1. González Jiménez E, Aguilar Cordero MJ, Padilla LóPEz CA, García GARcía I. Obesidad monogénica humana: papel del sistema leptina-melanocortina en la regulación de la ingesta de alimentos y el peso corporal en humanos. An Sist Sanit Navar 2012; 35: 285-293.

2. FaWCETT KA, Barroso I. The genetics of obesity: FTO leads the way. Trends Genet 2010; 26 : 266-274.

3. Bradfield JP, Taal HR, Timpson NJ, Scherag A, Lecoeur C, Warrington NM et al. A genome-wide association meta-analysis identifies new childhood obesity loci. Nat Genet 2012; 44 : 526-531.

4. Ahmad T, Chasman DI, Mora S, Paré G, Cook NG, Buring JE, et al. The Fat-Mass and ObesityAssociated (FTO) Gene, Physical Activity, and Risk of Incident Cardiovascular Events in Caucasian Women. Am Heart J 2010; 160: 1163-1169. 
5. Gerken T, Girard CA, Tung YCL,3, Webby CJ, SAudeK V, Hewitson KS, et al. The ObesityAssociated FTO Gene Encodes a 2-Oxoglutarate-Dependent Nucleic Acid Demethylase. Science 2007; 318: 1469-1472.

6. Tseng YH, Cypess AM, KAHN CR. Cellular Bioenergetics as a Target for Obesity Therapy. Nat Rev Drug Discov 2010; 9: 465-482.

7. Chao PT, Yang L, AJa S, Moran TH, Bi S. Knockdown of NPY expression in the dorsomedial hypothalamus promotes development of brown adipocytes and prevents diet-induced obesity. Cell Metab 2011; 13: 573-583.
8. Cataletto M, Angulo M, Hertz G, Whitman B. Prader-Willi syndrome: A primer for clinicians. Int J Pediatr Endocrinol (revista electrónica) 2011; (consultado 15-12-2012): 12. Disponible en: http://www.ncbi.nlm.nih.gov/ pmc/articles/PMC3217845/.

9. Butler MG, Bittel DC, Kibiryeva N, Cooley LD, Yu S. An Interstitial 15q11-q14 Deletion: Expanded Prader-Willi Syndrome Phenotype. Am J Med Genet A 2010; 152A: 404-408.

10. Budisteanu M, Barca D, Chirieac SM, MagureaNU S. Cohen syndrome - a rare genetic cause of hypotonia in children. Maedica (Buchar) 2010; 5: 56-61. 
